\title{
Escrever para aprender no ensino básico: Das conceções dos professores... às práticas dos alunos
}

\author{
Mariana Oliveira Pinto ${ }^{i}$ \\ Escola Superior de Educação de Lisboa, Portugal \\ Luísa Álvares Pereiraii \\ Universidade de Aveiro, Portugal
}

Resumo

Este artigo assenta na problemática da escrita como objeto de construção de conhecimentos e acentua a importância de os professores fazerem uma mediação da aprendizagem desta vertente da escrita. $\mathrm{O}$ objetivo deste texto é apresentar alguns resultados de um estudo no qual se analisam, num primeiro momento, as conceções e práticas de professores dos três ciclos do ensino básico e, posteriormente, as atividades de seleção de informação e escrita de uma exposição dos alunos de uma turma do $4^{\circ}$ ano de escolaridade. Os resultados evidenciam ausência de critérios específicos de avaliação e utilização de instruções de escrita pouco orientadoras da produção de um determinado (género de) texto por parte dos alunos. Por sua vez, estes revelaram dificuldades quer na seleção de informação, quer na produção do género pedido, já que o texto final apresenta uma colagem de partes de textos lidos, sem qualquer configuração textual regida pelo género.

Palavras-chave

Escrever para aprender; Exposição escrita; Ensino básico; Géneros textuais 


\section{Introdução1}

A constatação de que as dificuldades de escrita nas diferentes disciplinas constituíam um obstáculo às aprendizagens dos alunos fez emergir diferentes movimentos pedagógicos cujo enfoque se centrava na definição das estratégias propiciadoras da aprendizagem efetiva da escrita em todas as disciplinas (Applebee, 1984; Bazerman et al., 2005; Catel, 2001; Emig, 1977; Tynjälä, Mason, \& Lonka, 2001). Nascido primeiramente em Inglaterra, nos finais dos anos 60, sob a influência de Britton, o movimento Write-to-Learn teve um enorme sucesso nos Estados Unidos, num momento em que, face às dificuldades de escrita manifestadas pelos alunos à entrada no ensino superior, se equacionava a necessidade de lhes serem proporcionados cursos de escrita, integrados ou não, nos cursos científicos (Frank \& Soven, 1996; Rice, 1998).

O foco da investigação didática começa a centrar-se na necessidade de se construir um maior conhecimento sobre o papel efetivo da escrita na aprendizagem conceptual dos alunos, no sentido de se equacionar quais os textos que melhor podem favorecer tais aprendizagens, e quando e como a escrita para construção de conhecimentos deveria ser iniciada. Emerge, pois, a ideia de que a aprendizagem de conteúdos não podia efetivar-se com uma simples "ajuda didática" (Catel, 2001, p. 18) pressupondo, pelo contrário, um trabalho explícito e continuado em todas as disciplinas curriculares (Knight \& McKelvie, 1986; Stahl, King, \& Henk, 1991).

Em contexto nacional, só muito recentemente o "Escrever para Aprender" encontra a sua legitimação pedagógica no discurso pedagógico oficial. De facto, a designação aparece pela primeira vez, nos textos programáticos, no Programa de Português do Ensino Básico, homologado em 2009, doravante PPEB (Reis et al., 2009) ${ }^{2}$, ou seja, vinculado apenas à disciplina de língua. $\mathrm{Na}$ realidade, muito embora se considere, nos documentos programáticos das diferentes disciplinas curriculares, que as competências de escrita são condição para o sucesso escolar, o trabalho que os alunos aí desenvolvem limita-se, essencialmente, à "cópia de conceitos", "registo de sumários" e "respostas a questões" (Blaser, 2007; Castelló, 2008; Dionísio, Pereira, \& Viseu, 2011).

Muitos estudos parecem, de facto, corroborar a ideia de que, embora muitos professores afirmem a importância da dimensão epistémica da escrita, 
desconhecem como podem favorecer a aprendizagem dos conteúdos disciplinares e dos géneros textuais para aprender através de um trabalho com a escrita, em interação com a leitura (Blaser, 2007; Pereira, 2003, 2004c). Quando confrontados quer com a necessidade de planificar propostas de trabalho de escrita de textos destes géneros, quer com a definição de critérios de avaliação dos textos produzidos pelos alunos, muitos professores têm alguma dificuldade em evidenciar, por um lado, quais os aspetos a avaliar em cada dimensão que constitui o objeto texto, e que possibilitam distingui-lo, por exemplo, de um texto de outro género, e, por outro lado, e em consequência do pressuposto anterior, planificar atividades específicas em função do género a produzir (Pinto \& Pereira, 2006).

Ora, escrever um artigo enciclopédico, uma exposição escrita ou um artigo de divulgação, por exemplo, tem por base uma situação definida por elementos distintos; a escolha de um género é determinada pela esfera social, pelas necessidades da temática, pelo conjunto dos participantes e pela vontade enunciativa ou intenção do locutor (Marcuschi, 2005; Schneuwly \& Dolz, 2004). Tal implica que quer a organização global do conteúdo do texto, quer os mecanismos de textualização e discursivos a utilizar variem em função da consideração de tais variáveis, pelo que o ensino da escrita (e dos textos) não se compadece com atividades soltas e pontuais que caracterizam muitas das práticas letivas (Pereira, 2004a, 2004b). Pelo contrário, o agir do professor deverá ser orientado por "um conjunto de atividades organizadas, de maneira sistemática, em torno de um género textual" (Dolz, Noverraz, \& Schneuwly, 2004, p. 82; 2001). Tais atividades deverão estar assentes na construção de um modelo didático do género - "um objeto descritivo e operacional, construído para apreender o fenómeno complexo da aprendizagem de um género" -, que permita fazer emergir as diferentes dimensões que constituem determinado género, e quais as que devem ser ensinadas num determinado ano da escolaridade e para determinados alunos (Pietro, Erard, \& Kaneman-Pougatch, 1996).

Este princípio, que está na base do ensino da escrita de géneros textuais, atribui aos textos funções sociocomunicativas, ou, como afirmam Schneuwly e Dolz (2004), os géneros são formas de realizar linguisticamente objetivos específicos em situações sociais particulares. Configurando-se a escola como um "lugar social", no qual circulam géneros muito distintos, os 
contextos sociocomunicativos deverão, então, ser criados no sentido de os aproximar o mais possível dos contextos reais, tornando consciente para os alunos a possibilidade de ocorrência/ não ocorrência de diferentes géneros em contextos específicos.

Assim, por exemplo, quando é solicitada ao aluno a escrita de um texto sobre um animal, sem que se tenha explicitado o contexto de produção/ circulação do texto a produzir, o texto final poderá configurar uma multiplicidade de géneros: uma exposição escrita, um artigo de divulgação, um anúncio, uma notícia, uma fábula, entre outros. A prática parece mostrar que, perante tal proposta de escrita descontextualizada, a tendência dos alunos, especialmente dos mais novos, vai no sentido da produção de um texto no qual predominam sequências narrativas ficcionais (normalmente designados, em contexto escolar, por textos narrativos); esta tendência é explicável pela predominância da produção destes textos no currículo escolar.

Assim, a consideração dos destinatários, das funções do texto, dos conteúdos a textualizar e do suporte no qual o texto será divulgado poderá ajudar quem escreve a tomar decisões sobre o género a produzir, de entre um leque mais ou menos alargado de possibilidades num contexto determinado. Nos exemplos apresentados para a situação de escrita de um texto sobre um animal, a consideração das funções "expor", "apresentar um acontecimento", ou "manifestar um ponto de vista", por exemplo, poderá dar origem, respetivamente, a uma exposição escrita, a uma notícia e a um artigo de opinião.

Definido o género a produzir, torna-se necessário tomar decisões relativamente aos conteúdos a textualizar e à organização desses conteúdos (à sua disposição) - macroestrutura - de acordo com o plano do texto (diferentes partes ou secções do texto). Tal conhecimento, fundamental para a produção de qualquer género, assume particular importância nos textos inscritos nos géneros específicos que enformam a escrita para explicitação de conhecimentos. Neste contexto, muitos dos textos que os alunos produzem constituem-se como "lugares" de explicitação da informação que selecionam do que leem ou ouvem. Ora, muitos destes textos que funcionam como "fonte" dos conteúdos são muitas vezes de géneros distintos daquele que se pretende escrever, implicando a (re)organização dos conteúdos selecionados em função do plano do texto do género a produzir. De facto, e uma vez que 
os mesmos textos "fonte" poderão dar origem a diferentes géneros textuais, o desconhecimento do plano do texto a produzir poderá dar origem a um texto cuja organização decorre não do género a produzir, mas que corresponda a um texto de um dos géneros que leu.

Retome-se o exemplo dado anteriormente: a produção de um texto sobre um animal selecionando como género a produzir, de entre um leque de possibilidades mais ou menos alargado, a exposição escrita. Para a produção deste género, marcadamente escolar, e cujo plano é relativamente estereotipado - apresentação, descrição e conclusão ou fechamento (Pietro \& Schneuwly, 2003) -, são muitas vezes solicitadas aos alunos a leitura e pesquisa em textos de géneros distintos (artigos de enciclopédia, textos de manuais escolares e artigos de divulgação, por exemplo), que funcionam como "fonte" de conteúdos sobre os quais deverão ser realizadas tarefas de leitura e seleção de informação. Ao produzir o texto pedido, desconhecendo o plano que configura a exposição escrita, o aluno poderá ou produzir um texto que se aproxime não daquele que lhe foi solicitado, mas de um dos géneros que leu, ou, em muitos casos, escrever (copiando) frases e/ou parágrafos sem qualquer articulação entre si, dando origem a um produto final dificilmente identificável como texto.

Saber selecionar o género textual a produzir, de acordo com as variáveis já apresentadas, conhecer o plano de texto que o configura e os mecanismos de textualização e discursivos que conferem ao texto coerência temática e pragmática (Bronckart, 1997) constituem-se, então, como conhecimentos que funcionam como um "caderno de encargos" e, por isso, como um "redutor da complexidade", pois o aluno tem, à partida, controlo sobre um determinado (e determinante) nível de regulação para a configuração do texto a produzir (Pereira, 2008).

Do que fica dito, infere-se a importância de um trabalho didático que proporcione aos alunos momentos de trabalho de análise e produção de textos de diferentes géneros, aprendendo quer a selecionar, organizar e hierarquizar a informação que vão construindo, através dos textos lidos ou ouvidos, quer a analisar textos que funcionem como exemplares do género (Pereira, 2008), autênticos ou fabricados, para pôr em evidência certos aspetos do funcionamento textual, para deles fazer emergir as suas características. Este modo de trabalho poderá levar o aluno a aprender a 
textualizar o conhecimento adquirido de acordo com as características e propriedades configuradoras dos diferentes géneros textuais.

É na perspetiva defendida que se pode afirmar a relevância em formar (futuros) professores e alunos para (re)conhecerem os parâmetros definitórios de muitos géneros (textuais) para aprender, dominando, assim, em cada situação de escrita, o "caderno de encargos" do género a produzir (Pereira \& Cardoso, 2013). O estudo que se apresenta neste texto assenta na tomada de consciência desta necessidade e parte, pois, da importância de que se reveste a escrita quer no sucesso dos alunos, quer nas suas aprendizagens, e da necessidade de os professores conseguirem fazer uma mediação desta vertente epistémica da escrita. Este estudo foi realizado num contexto de formação de professores de Português do ensino básico e no contexto de uma turma de $4 .^{\circ}$ ano de escolaridade em que se mobilizou um dispositivo didático para o ensino da exposição escrita, assumido como um "modelo didático do género".

Os resultados que aqui se apresentam dizem respeito às fases 1 e 2 do plano de formação, nas quais se procurou conhecer as práticas dos professores e alunos relativamente à dimensão da escrita para aprender ${ }^{3}$. De facto, assume-se como fundamental esta fase prévia, uma vez que permite partilhar e refletir sobre as representações, conhecimentos e estratégias, quer dos professores, quer dos alunos, constituindo-se como ponto de partida para o desenvolvimento das etapas seguintes de planificação, implementação e avaliação do dispositivo didático.

\section{Práticas de escrita no ensino básico: Escrita de textos para a construção e explicitação de conhecimentos}

Uma vez que é importante que os professores consigam integrar no seu trabalho didático momentos que permitam que os alunos aprendam a produzir textos para explicitar conhecimentos, constitui-se como fundamental que haja uma formação de professores que integre esta dimensão e em que seja possível conceber e testar dispositivos didáticos que lhes permitam desenvolver conhecimentos sobre o ensino de diferentes géneros que configuram a dimensão do escrever para aprender. 
Assumindo, tal como Pereira (2008), que é importante que o professor participe na definição dos dispositivos com que trabalha, não tanto no sentido de que os fabrica ele próprio, mas no sentido de que pode lê-los e compreender o seu significado mais profundo, foi planificada e desenvolvida uma ação de formação com professores do $1 .^{\circ}$ ciclo e professores de Português do $2 .^{\circ}$ e $3 .^{\circ}$ ciclos do ensino básico, entre janeiro e junho de 2013 , cujo objetivo fundamental foi o de planificar, construir e implementar dispositivos didáticos para o ensino da escrita para a construção de conhecimentos, e avaliar o seu efeito na qualidade dos textos dos alunos nos diferentes ciclos do ensino básico.

Apesar de termos em conta, no contexto deste artigo, apenas os dados das fases 1 e 2, o estudo desenvolvido entre janeiro e junho, num agrupamento de escolas da zona norte do país, incluiu, também, na fase 3, a implementação e avaliação de um dispositivo didático para o ensino da escrita.

\section{Fase 1: Caracterização das práticas dos professores}

\section{Condições de realização}

Os dados a apresentar neste ponto decorrem da primeira fase do programa de formação sobre o ensino da escrita, com catorze professores dos três ciclos de ensino básico, divididos pelos seguintes anos de cada ciclo: seis professores do $1^{\circ}$ ciclo (um do $2 .^{\circ}$ ano, quatro do $3 .^{\circ}$ ano e um do $4 .^{\circ}$ ano); três professores do $2^{\circ}$ ciclo (todos do $6 .^{\circ}$ ano); cinco professores do $3^{\circ}$ ciclo (um do $7 .^{\circ}$ ano, dois do $8 .^{\circ}$ ano e dois do 9. ano). A seleção dos formandos foi da responsabilidade da direção do agrupamento, à qual foi solicitada a seleção de professores de acordo com o seguinte critério: professores do $1 .^{\circ}$ ciclo; professores de Português dos $2 .^{\circ}$ e $3 .^{\circ}$ ciclos. O número de formandos e as horas de formação (50 horas) foram os que estão previstos para a modalidade "oficina de formação" nas orientações definidas pelo Conselho Científico-Pedagógico da Formação Contínua, entidade responsável pela acreditação dos programas de formação contínua.

\section{Objetivos}

$\mathrm{Na}$ fase 1 do estudo, pretendeu-se, tal como já foi referido, conhecer as práticas dos professores sobre o trabalho habitualmente desenvolvido em 
sala de aula, no que diz respeito à escrita. Assim, foi definido como objetivo: caracterizar as práticas dos professores do ensino básico relativamente à dimensão da escrita para construção de conhecimentos, no que respeita a: i) instruções que enunciam na fase em que os alunos selecionam informação para a escrita do texto; ii) instruções que enunciam na fase de produção do texto; ii) critérios de avaliação dos textos.

Para a concretização do objetivo definido, optou-se por solicitar aos formandos que planificassem e implementassem, de acordo com a sua prática corrente, uma atividade de produção de uma exposição escrita. A seleção do género a produzir pelos alunos foi da responsabilidade dos formandos, a partir de um conjunto de possibilidades sugeridas nos documentos oficiais. Não foram propositadamente explicitadas quaisquer caraterísticas configuradoras do texto em questão, uma vez que o objetivo desta proposta era, justamente, conhecer e analisar as representações e práticas dos professores em formação, relativamente ao género a produzir. Importa referir que não foi levantada qualquer questão ou pedido qualquer esclarecimento por parte dos formandos.

Para a realização da tarefa, os docentes deveriam ter em conta os seguintes elementos: (i) selecionar um tema de acordo com o ano e com a turma; (ii) selecionar dois textos sobre o tema escolhido com extensões diferentes e manchas gráficas diferentes (por exemplo, um com subtítulos e outro "corrido"), e distribui-los aos alunos como "textos fonte" nos quais teriam de selecionar a informação sobre o tema; (iii) distribuir uma folha branca de formato A4 para notas ou apontamentos; (iv) definir as instruções de leitura (seleção de informação) e escrita; e definir os critérios de avaliação dos textos finais.

As atividades em sala de aula deveriam ser realizadas em dois dias: no primeiro dia, a leitura, seleção de informação e tomada de notas; no segundo dia, produção de uma exposição escrita sobre o tema sem o recurso aos textos-fonte (com base apenas nos apontamentos/notas de cada aluno).

Todos os professores selecionaram os textos em função do tema que estavam a desenvolver no contexto da disciplina de Português (Estudo do Meio, no caso dos professores do $1 .^{\circ}$ ciclo), e realizaram a tarefa nos dois dias previstos. 


\section{Apresentação e análise dos dados}

A recolha de dados foi efetuada através de uma grelha de planificação distribuída aos professores, na qual constavam como campos a preencher: (i) ano de escolaridade e produção textual (género); ii) descrição da tarefa a produzir e instruções (seleção de informação e escrita do texto); e (iii) critérios de avaliação dos textos dos alunos.

Procedeu-se à análise de conteúdo, definindo-se categorias decorrentes dos materiais recolhidos, e à sua codificação e posterior quantificação com o recurso ao NVivo 10.

\subsection{Tarefas propostas para a escrita de uma exposição escrita}

i) Seleção de informação - instruções dos professores

$\mathrm{Na}$ análise deste tópico foram consideradas as instruções definidas pelos professores nas respetivas planificações, instruções essas posteriormente comparadas com as registadas em áudio nas sessões.

Confirmando alguns dados já apresentados por outros estudos, dos quais se destaca, a título de exemplo, Piolat e Boch (2004), também para estes professores a tarefa de sublinhar constitui a estratégia privilegiada na leitura e seleção de informação. De facto, apenas um professor, de entre os catorze considerados, não deu como instrução "ler com atenção" e "sublinhar o mais importante". Quando questionado sobre este aspeto, o professor em causa, da turma do $4 .{ }^{\circ}$ ano, referiu que não deu qualquer instrução, uma vez que pretendia identificar e perceber quais as estratégias que os alunos usavam na tarefa de seleção de informação.

Também à imagem do que vem sendo referido em outros estudos (Blaser, 2007; Castelló, 2008), importa sublinhar que os professores dos três ciclos não desenvolvem (nem nunca desenvolveram) com os alunos qualquer atividade intencionalmente desenhada para a seleção de informação ou distinção entre informação essencial e acessória, muito embora sejam desempenhos que constam dos documentos oficiais como transversais aos três ciclos.

Quando questionados sobre a importância de que se reveste o pedido de sublinhar nas suas instruções, afirmaram não ter uma razão especial para o fazer, assumindo essa prática como um exercício que naturalmente está associado à tarefa de seleção de informação. 
Importará, pois, face a estes resultados, analisar o que os alunos sublinham, como sublinham e de que forma tal estratégia se reflete no conteúdo e na forma dos textos produzidos; esta análise constituirá o objeto de reflexão na fase 2 deste estudo. Para já, e depois de termos compreendido a forma como os professores consideram as tarefas de construção de conhecimentos - como algo que os alunos já devem saber -, vamos caracterizar a forma como os professores propõem a própria tarefa de escrita do texto.

ii) Escrita do texto - instruções dos professores

Pretendia-se, pois, antes de mais, identificar quais as instruções apresentadas aos alunos para a realização da tarefa de escrita da exposição. Tal como já foi referido anteriormente, esta atividade teve lugar no segundo dia da intervenção, e os alunos tiveram de produzir o texto com base apenas nos respetivos apontamentos. Importa referir que nenhum professor explicitou o género a produzir no primeiro dia da tarefa (leitura e seleção de informação), nem desenvolveu qualquer trabalho prévio com os alunos no sentido de tornar mais claro qual ou quais os interlocutores do texto a produzir. Tal significa que os alunos leram e selecionaram a informação nos textos-fonte sem qualquer conhecimento prévio sobre o objetivo da tarefa ou do texto a produzir posteriormente. As instruções foram, portanto, definidas por cada um dos professores e apresentadas por escrito aos alunos.

A análise dos dados permite traçar um quadro com a seguinte configuração: os professores deram prioridade à descrição da tarefa e não às características do género a produzir, uma vez que a maioria $(57 \%)$ deu a seguinte instrução aos alunos: "escrevam um texto com os apontamentos" e "faz um trabalho escrito sobre..." (7\%). Por outro lado, para $25 \%$ dos professores, o resumo e a exposição (assumido para os professores como texto expositivo) são géneros com as mesmas características e funções. Foi ainda possível verificar que $14 \%$ dos professores deram como instrução "escreve um texto com o que há em comum nos dois textos", o que implica que o texto a produzir pelos alunos deverá ter como conteúdos apenas os tópicos que ocorrem nos dois textos lidos, não devendo ser considerados aqueles que estão presentes apenas em um dos textos. Alguma da deriva terminológica que caracteriza o discurso oficial e pedagógico relativamente à 
classificação (e designação) dos textos (Pinto, 2014, pp. 23-34) pode, também, explicar as dificuldades que os professores sentiram, não só na definição do género a trabalhar, como na consideração de quais as características e propriedades dos textos a produzir pelos alunos.

De facto, parece confirmar-se, assim, a ideia de que os professores desconhecem as particularidades e características dos géneros e dos textos "para aprender", podendo tal significar alguma dificuldade na preparação das atividades especificamente orientadas para o trabalho com estes géneros e pouca especificidade e rigor na análise e avaliação dos textos produzidos pelos alunos.

Este aspeto será analisado no ponto seguinte, no qual se pretende identificar quais os critérios de avaliação dos textos dos alunos que os professores definem e quais os níveis de explicitação (e diferenciação) que os professores estabelecem para cada critério definido.

iii) Critérios de avaliação

Neste ponto da análise procurou verificar-se, por um lado, se os professores definiam critérios distintos para as diferentes fases da tarefa (seleção de informação e escrita do texto), e, por outro lado, se os critérios de avaliação do texto final correspondiam a critérios gerais transversais a qualquer género ou se, pelo contrário, definiam critérios de avaliação centrados na exposição escrita.

A organização do texto e a coerência constituem-se como categorias mais representadas (71\%), ficando, no entanto, por esclarecer quais os critérios mais específicos considerados em cada uma dessas categorias. Quando questionados sobre o que consideram ser a coerência do texto e a organização textual, as respostas dadas constituem "paráfrases" dos conceitos: texto bem organizado, ideias apresentadas de forma coerente.

Os critérios apresentados parecem, aliás, decorrer de uma lista de tópicos que fazem parte, tradicionalmente, do léxico específico da disciplina, acessível aos professores através dos documentos oficiais, dos manuais, etc. $\mathrm{Na}$ verdade, quando se analisam os critérios de classificação dos exames nacionais de Português definidos pelo Gabinete de Avaliação Educacional do Ministério de Educação português (GAVE) para o final do $2 .^{\circ}$ ciclo, verifica-se 
que os critérios aí definidos apresentam uma formulação semelhante à apresentada pelos professores. De igual modo, nestes documentos oficiais, tais critérios são os mesmos para os três ciclos e neles também não é apresentada qualquer explicação relativa a cada um dos critérios apresentados. No entanto, e como se pode ver na parte final do excerto do texto da prova de avaliação (GAVE) apresentado abaixo, caso o aluno não respeite "de forma inequívoca a instrução no que respeita ao tema e ao tipo de texto, deve ser classificado com zero pontos em todos os parâmetros": os descritores de níveis de desempenho da produção escrita integram os parâmetros

Tema e Tipologia; Coerência e Adequação da Informação; Estrutura e Coesão; Morfologia e Sintaxe; Repertório Vocabular; Ortografia. Caso o texto produzido pelo aluno não cumpra de forma inequívoca a instrução no que respeita ao tema e ao tipo de texto, deve ser classificado com zero pontos em todos os parâmetros ${ }^{4}$.

Regressando agora à análise em questão a partir do estudo nesta fase 1, os critérios de avaliação apresentados pelos professores não consideraram qualquer tópico específico que tivesse em conta o conteúdo da informação a selecionar. Ao definirem como critério apenas a fórmula "seleção de informação", torna-se difícil equacionar se se trata apenas de uma questão quantitativa (enumeração dos conteúdos/tópicos) ou se, para além deste aspeto, serão consideradas as questões de hierarquização dos conteúdos, o seu rigor e cientificidade, a forma como os alunos fazem paráfrases, etc.

Face às propostas de trabalho planificadas e implementadas pelos professores, importava caracterizar e compreender em que medida as opções então tomadas se refletiam nos desempenhos dos alunos, nomeadamente nas estratégias de leitura e seleção de informação utilizadas e na escrita do texto.

$\mathrm{Na}$ verdade, muitas das dificuldades que os alunos demonstram na escrita são, sobretudo, justificadas pelos professores pela falta de interesse que aqueles demonstram e pelas lacunas que vão acumulando ao longo da escolaridade; quase nunca são perspetivadas do ponto de vista da sua responsabilidade, isto é, das próprias práticas que desenvolvem (Pereira, 2004c). Neste sentido, perante alguma indecisão ou indefinição demonstradas pelos professores envolvidos neste estudo, quer nas tarefas e 
instruções a propor, quer na consideração de quais as propriedades configuradoras que caracterizam o género em questão, assim como as características do texto a produzir, tornava-se necessário que, de forma mais objetiva e explicitada, pudessem ver refletidos alguns dos eventuais "efeitos" das tarefas que implementaram nos desempenhos dos alunos. Trata-se, pois, de perceber, mais objetivamente, qual o entendimento dos alunos das tarefas propostas pelos professores.

Definiu-se, assim, como objetivo principal da fase 2, caracterizar e compreender as práticas de escrita dos alunos da turma do $4 .^{\circ}$ ano de escolaridade, verificando os seus desempenhos nas tarefas de seleção de informação e na redação do texto.

\section{Fase 2: Caracterização das práticas dos alunos}

\section{Amostra e objetivos}

Na segunda fase, o corpus de análise foi constituído pelas produções individuais dos alunos. Nesta fase, e no contexto deste artigo, apresentam-se apenas os dados relativos aos alunos da turma do $4^{\circ}$ ano de escolaridade (22 alunos), que corresponde à primeira turma que desenvolveu a atividade em sala de aula, e à única turma à qual não foi dada a instrução "lê com atenção e sublinha a informação mais importante". Pretende-se, assim, identificar qual ou quais as estratégias que os alunos utilizam na tarefa de seleção de informação, quando não Ihes é dada qualquer explicitação da tarefa.

Os dados a seguir apresentados organizam-se de acordo com as diferentes etapas da atividade desenvolvida - seleção de informação ( $1{ }^{\circ}$ dia) e escrita do texto (2. ${ }^{\circ}$ dia) -, e de acordo com os objetivos definidos: caracterizar as práticas de escrita dos alunos, identificando: i) as estratégias de seleção de informação utilizadas; e ii) as propriedades dos textos produzidos.

\section{Apresentação e análise dos dados}

2.1. Tarefas realizadas pelos alunos na escrita de uma exposição

i) Seleção de informação nos textos-fonte

Tratando-se da produção de um texto cuja função principal se enquadra na escrita para explicitação de conhecimentos, pretendeu-se que a 
informação a pôr em texto não decorresse apenas daquela de que os alunos já dispunham, mas que estes fossem confrontados com a necessidade de selecionar a informação em dois textos sobre o tema, os designados textosfonte, e que tornassem "visível" o resultado da leitura e da seleção de informação na tomada de notas - a escrita para construção de conhecimentos.

Assim, e neste ponto da análise, pretendeu verificar-se a forma como os alunos procederam para selecionar a informação nos dois textos-fonte, a partir da instrução dada pela professora da turma.

As categorias de análise são definidas de acordo com as estratégias utilizadas pelos alunos, uma vez que, numa primeira leitura "flutuante" dos textos-fonte, não se verificou qualquer outra marca para além dos sublinhados - não há notas nem apontamentos laterais. Assume-se, por isso, que sublinhar é, também para os alunos, a única estratégia à qual recorrem para ler e selecionar informação, e este aspeto é tanto mais relevante quanto a turma em causa corresponde à única a que não foi dada a instrução recorrente: "ler com atenção e sublinhar a informação mais importante".

Importava, pois, responder a três questões principais, no sentido de perceber o que leem, como leem e como definem ou determinam qual a informação mais importante a selecionar: (1) Quando os alunos têm mais do que um texto para ler e selecionar informação, consideram apenas um (qual) ou os dois textos?; (2) O que sublinham os alunos: palavras, frases ou parágrafos?; (3) Face ao tema a trabalhar, quais os critérios que utilizam para decidir qual a informação que consideram mais importante?

Para responder às questões enunciadas, procedeu-se à análise do corpus de acordo com as seguintes categorias:

i) identificação dos sublinhados nos textos-fonte (em que textos e em que extensão do texto);

ii) caracterização dos sublinhados (o que sublinham: conteúdos e unidades linguísticas - palavras, frases ou parágrafos).

Relativamente à identificação dos sublinhados dos alunos, foram analisados os textos-fonte 1 e 2 (cf. Anexo) com o objetivo de identificar o número de alunos que faz sublinhados nos textos lidos ${ }^{5}$. Quando os alunos têm mais do que um texto-fonte, parece haver uma tendência para ler e retirar 
informação apenas de um texto - apenas cinco alunos sublinharam os dois textos -, preferencialmente aquele cuja organização facilita a leitura (texto 1texto com subtítulos, 13 alunos). Dos 22 alunos da turma, apenas oito não sublinharam qualquer um dos textos-fonte. Este dado parece indicar que a tarefa de sublinhar se assume, também para os alunos, como fundamental na leitura e seleção de informação, uma vez que, tal como já foi referido, não lhes foi dada qualquer instrução nesse sentido.

Posteriormente, pretendeu-se identificar quais as estruturas linguísticas que os alunos sublinham nos textos. Para tal, foram definidas como categorias de análise: (i) palavras ou grupos de palavras; (ii) frases; (iii) parágrafos; e (iv) texto. O parágrafo constitui-se como a categoria mais valorizada pelos alunos, quer no texto 1 (nove alunos), quer no texto 2 (sete alunos), parecendo, pois, assumir-se como o "lugar" que concentra mais informação. Quando se comparam estes dados com os apontamentos/notas que os alunos tiram, verifica-se que há uma relação entre a estrutura que sublinham e aquela que anotam na folha. De facto, os apontamentos são, numa grande maioria (88\%), "textos corridos" que os alunos produzem, constituindo-se como cópias dos parágrafos que selecionaram.

Face à instrução dada pela professora nesta fase, os alunos só sabem qual o género textual a produzir posteriormente à tomada de notas, uma vez que não Ihes foi dada qualquer informação prévia sobre o objetivo e/ou formato do texto a produzir. No entanto, foi possível verificar que os textos finais são cópias dos rascunhos, que, por sua vez, são cópias dos apontamentos. Assim, tal procedimento parece significar que o texto final seria o mesmo independentemente do género solicitado. Parece, pois, confirmar-se a ideia de que a prática de pensar a escrita do texto em função dos objetivos, funções, destinatários, etc., não ocorre com estes alunos.

A análise permite, ainda, verificar que nem toda a informação sublinhada foi transposta para a folha de apontamentos, o que poderá significar que, ou a informação sublinhada não é considerada importante, ou os alunos realizam a tarefa sem lhe atribuir grande significado, dando-a por terminada quando já estão cansados.

Identificaram-se, assim, duas situações distintas: i) alunos que sublinham aspetos relativos a cada um dos tópicos do conteúdo do texto (características, habitat, etc.) e não os anotam na folha de apontamentos; ii) 
alunos que não sublinham informação, mas consideram-na nos apontamentos.

Sublinhar é, para alguns alunos, uma operação de "pintura textual", que implica uma seleção prévia de lápis de muitas cores e uma combinação de tons. Uma das alunas ficou por momentos a olhar para os textos-fonte e, em simultâneo, para os lápis de que dispunha. Selecionou várias cores e pintou todo o texto (cada parágrafo com uma cor). Só depois desta operação é que leu o texto. Este exemplo parece evidenciar a ideia de que os alunos cumprem um ritual que não entendem, ou ao qual não atribuem qualquer significado, seja pelo desconhecimento da tarefa a realizar, seja pela ausência de sentido para a sua realização. De facto, para esta aluna parece ser muito mais importante tornar visível para a professora que está a ler do que efetivamente ler para se apropriar de conhecimentos, o que, inevitavelmente, se refletirá no texto a produzir. Para outros alunos, sublinhar é assumido num sentido diferente: riscam completamente frases e parágrafos considerados pouco importantes, deixando à vista apenas a informação essencial, tal como é visível neste exemplo do aluno A8 (Figura 1).

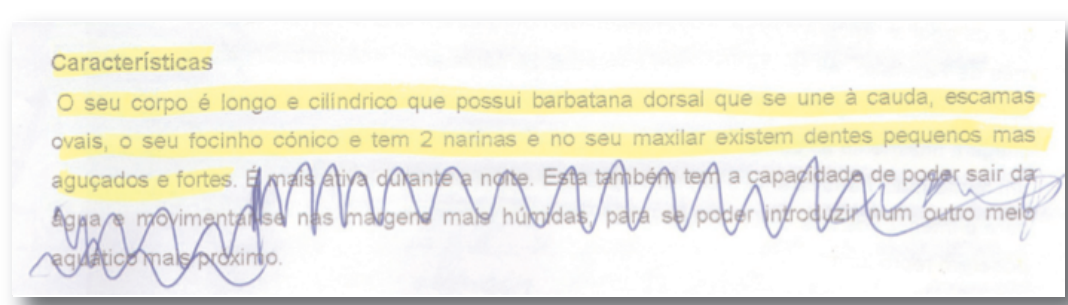

Figura 1. Exemplo de seleção de informação do aluno A8

Há ainda alunos que vão construindo o texto à medida da leitura que vão fazendo. Em cada frase riscam palavras que não vão utilizar, deixando visível a frase tal como a transcrevem para os apontamentos e, posteriormente, para o texto. Nestes casos, tal operação ocorre apenas numa extensão muito reduzida do texto, sendo todo o restante deixado sem qualquer sublinhado ou risco.

A tarefa de sublinhar, assumida por professores e alunos como estratégia essencial no processo de leitura para seleção de informação, 
parece configurar uma prática que em nada contribui para o desenvolvimento de competências de leitura para seleção de informação, podendo, em determinados casos, condicionar negativamente o texto que o aluno produz. Este aspeto será analisado no ponto seguinte.

ii) Escrita do texto - práticas dos alunos

Neste ponto procurou analisar-se as práticas dos alunos na produção de um texto para construção do conhecimento - exposição escrita -, selecionando como corpus de análise os textos finais, produzidos a partir dos apontamentos e do texto-rascunho.

No contexto deste artigo, definiram-se como categorias de análise as seguintes: i) conteúdos textualizados; ii) plano do texto da exposição escrita; e iii) estratégias de textualização. A explicitação de cada uma das categorias e algumas conclusões decorrentes da análise efetuada são apresentadas nos pontos seguintes.

\section{Conteúdos textualizados}

Neste ponto, analisaram-se os oito subtemas representados nos textos-fonte - classe, local de nascimento, características, alimentação, reprodução, habitat, comportamentos e curiosidades - e identificou-se, num primeiro momento, a ocorrência de cada um deles nos textos finais dos alunos.

Todos os subtemas presentes nos textos-fonte correspondem a designações que fazem parte do conhecimento prévio dos alunos, uma vez que fazem parte do conteúdo programático da disciplina de Estudo do Meio, desde os primeiros anos da escolaridade. Assim, o facto de privilegiarem determinados subtemas relativamente a outros não pode ser explicado pela complexidade/não complexidade associada nem às designações, nem à natureza do conteúdo explicitada nos diferentes subtemas. No entanto, não há nenhum subtema que esteja presente nos textos de todos os alunos. Este facto torna visível, desde logo, que a seleção de informação efetuada não teve como critério fundamental a sua importância ou relevância; torna-se também visível que os subtemas mais presentes são os que ocorrem, nos textos-fonte, nos parágrafos iniciais. 
Quando se compararam os sublinhados nos textos-fonte com os apontamentos, verificou-se haver uma tendência dos alunos, ainda que não muito acentuada, para reduzir os subtemas que efetivamente consideraram nos apontamentos face àqueles que sublinharam. Tratando-se, à partida, de subtemas cujo "grau de importância" era mais ou menos equivalente, até mesmo porque, e de acordo com a professora, se relacionavam com aqueles que, normalmente, trabalhavam no âmbito do estudo dos animais, foi um dado importante perceber que na tarefa de leitura e seleção de informação, e posterior tomada de notas, os alunos não tinham sido capazes de mobilizar tal conhecimento já (em teoria) adquirido no Estudo do Meio, relativamente aos subtemas que se tornam importantes considerar quando se aprendem "coisas" sobre os animais. De facto, tal (in)capacidade, demonstrada quer pelo número de subtemas sublinhados, quer por aqueles que efetivamente consideraram nos apontamentos, foi considerada como "inesperada" pela professora.

Ora, no sentido de tornar ainda mais visível a relação estabelecida entre a informação selecionada e textualizada, procurou perceber-se, também, se tal tendência para reduzir a informação presente no textos-fonte, sublinhada e considerada nos apontamentos, era igualmente visível na passagem dos apontamentos para os textos finais, o que veio efetivamente a confirmar-se. Na realidade, dos 22 alunos da turma, apenas sete consideraram os mesmos subtemas nos apontamentos e nos textos finais. De facto, a redução de informação parece assumir, nesta tarefa, uma grande visibilidade, uma vez que quinze alunos eliminaram subtemas na passagem dos apontamentos para o texto, parecendo, eventualmente, querer evitar a cópia.

Os dados apontam, assim, para a conclusão de que a tarefa de sublinhar, tal como os alunos a (não) entendem, prefigura uma estratégia de seleção de informação que em nada favorece nem a aquisição de conhecimentos, nem a produção do texto, o que leva a reforçar a necessidade de ser incorporado, nas práticas letivas, um novo foco de ação didática assente nas estratégias efetivas de seleção de informação e tomada de notas (Applebee, 1984; Barré-De-Miniac, 2003; Bosch \& Piolat, 2004; Castelló, 2008; Dolz, 2003; Gallego, Alvarez, \& Eulate, 2008; Pinto, 2013; Pinto \& Pereira, 2006; Piolat \& Boch, 2004). 


\section{Plano do texto}

Retoma-se agora um princípio já enunciado: na produção de um género textual torna-se necessário tomar decisões relativamente à macroestrutura textual, isto é, aos conteúdos a textualizar e à sua organização de acordo com o plano do texto, isto é, de acordo com as diferentes partes ou secções do texto.

Se, na fase 1 deste estudo, em que se procurou identificar as instruções mais comuns para a realização de tarefas de produção de exposição escrita, se verificou que os professores optaram por propor aos alunos a produção de um texto sem o ensino explícito das suas propriedades genológicas, não será certamente expectável que os alunos as conheçam e as mobilizem nos textos produzidos. Na realidade, tal como ficou evidente na secção anterior, quase todos os alunos produzem um texto-rascunho no momento de seleção de informação e, quando lhes é pedida a tarefa de produção de uma exposição escrita, limitam-se a copiar o texto-rascunho.

Assim, não é, portanto, de estranhar que os "textos" finais produzidos pelos alunos sejam textos que não obedecem à grande maioria dos parâmetros que definem uma exposição escrita (ou mesmo qualquer outro género textual), nomeadamente ao não contemplarem qualquer delimitação das diferentes partes, aspeto que desde logo ressalta de uma primeira leitura superficial dos textos dos alunos. Quando se analisam os textos, verifica-se que $90 \%$ são constituídos por um único parágrafo, independentemente do número de tópicos apresentados.

\section{Estratégias de textualização}

A leitura e análise das produções finais dos alunos permitiu-nos ainda verificar quais as estratégias mais mobilizadas, a saber:

i) cópia de frases com supressão, inserção ou substituição de palavras

A cópia de frases com supressão, que afeta a gramaticalidade da frase, ocorre quando o aluno retira palavras de uma frase. Nestes casos, a frase produzida apresenta problemas de natureza sintática (e semântica) pela ausência de um ou mais constituintes obrigatórios (grupo nomimal ou verbal) ou de argumentos selecionados pelo verbo, nome ou adjetivo. Um exemplo de supressão verifica-se na produção do aluno A1: 
Após um longo ciclo de vida dentro de água continentais entre 5, e 12 anos. Este animal passa a sua vida dentro da água doce emigra ocorre entre os 6 anos e os 12 anos. (A1)

Outra estratégia utilizada é a substituição de palavras ou expressões, provocando, muitas vezes, incorreções de natureza científica, como se verifica no exemplo seguinte, no qual o aluno apresenta a enguia:

A enguia é um mamífero. (Aluno A17)

A inserção de palavras pode ter como consequência a utilização de léxico não adequado. A propósito da caracterização da enguia, um aluno escreve:

O seu corpo é naturalmente longo e também é cilíndrico. Tem barbatanas extremamente dorsais... (Aluno A12)

ii) contração da informação

Esta estratégia afeta a cientificidade dos conceitos, embora as frases produzidas sejam, na maior parte dos casos, gramaticalmente corretas, como se pode verificar no exemplo seguinte. O texto-fonte refere que "A fêmea é maior do que o macho, atingindo normalmente medidas que vão dos $30 \mathrm{~cm}$ a $1 \mathrm{~m}$ ". Referindo-se a esta característica, o aluno escreve:

A fêmea é maior do que o macho podendo ultrapassar os $30 \mathrm{~cm}$ de altura. (Aluno A10)

iii) seleção de frases dos parágrafos

$\mathrm{Na}$ seleção de frases de parágrafos, os alunos copiam uma frase ou partes de uma frase de mais do que um parágrafo e sobrepõem-nas num único parágrafo. O texto do aluno A21 é, como se pode ver na descrição seguinte, semelhante a uma listagem das características da enguia:

A enguia nasce no oceano Atlântico, morre com cerca de 55 anos. Pertence ao género Anguilla. Tem um ciclo de vida no mar e na água doce. A enguia tem dentes pequenos e fortes, 2 narinas e o corpo longo e cilíndrico. A enguia tem uma barbatana que se une à cauda. A enguia fêmea encontra-se na parte superior dos cursos de água e os machos nos estuários. A enguia é um animal omnívoro. As enguias reproduzem-se entre os 5 e 12 anos nas profundezas por volta dos 300 aos $700 \mathrm{~m}$. A temperatura é 16 ou 17 graus. (A21) 
De facto, as estratégias (ou a ausência destas) que utilizaram para selecionar a informação (o que escrever?) e o desconhecimento manifestado das características do género a produzir (como escrever?) poderão, mesmo, ter influenciado negativamente a escrita do texto: ao sublinharem, aparentemente, sem tomarem decisões sobre qual a informação essencial a selecionar, e como selecioná-la face ao conteúdo e ao objetivo do texto a produzir, os textos produzidos configuram não o género textual solicitado, mas uma cópia do texto-fonte ao qual aplicaram supressões, inserções e substituições sem, aparentemente, terem tido outro objetivo que não fosse "mudar alguma coisa para não ficar igual".

As produções dos alunos representam, pois, uma conceção de texto como sinónimo de escrita de frases, algumas delas semântica e sintaticamente incorretas, sem qualquer articulação entre elas. Os alunos parecem, assim, cumprir um ritual e não a produção efetiva de um texto com um propósito concreto e que requer, por isso, o controlo de certas variáveis e a mobilização de procedimentos cognitivos e linguístico-textuais.

Este cenário reforça, assim, a ideia já anteriormente apresentada de que qualquer ação didática implica o princípio da sequencialidade, contrário às atividades pontuais e descontextualizadas. A adoção de tal princípio implica, reforça-se uma vez mais, que as atividades a implementar com os alunos tenham na base um conhecimento aprofundado do objeto a ensinar, uma vez que só assim se torna possível considerar as opções tomadas e aquelas que importa tomar, de forma a tornar as aprendizagens dos alunos efetivas e mais significativas.

\section{Considerações finais}

O objetivo deste artigo foi, como já referimos, apresentar alguns resultados parcelares de um estudo realizado no contexto de um programa de formação para o ensino da escrita de "géneros escolares para aprender".

Neste artigo, no qual se privilegiaram as conceções e práticas dos professores dos três ciclos do ensino básico e as práticas dos alunos de uma turma do $4 .^{\circ}$ ano de escolaridade, apresentámos, num primeiro momento, alguns dados sobre as práticas dos professores relativamente às instruções de escrita que enunciam e aos critérios de avaliação dos textos que definem, 
e, posteriormente, analisaram-se as propostas de atividades de seleção de informação e escrita de uma exposição dos alunos de uma turma do $4^{\circ}$ ano de escolaridade.

A caracterização das práticas dos professores do ensino básico envolvidos neste estudo, relativamente ao trabalho que desenvolvem com a escrita para aprender, permitiu confirmar os dados que emergem de outros estudos já realizados (Castelló, 2008; Dolz, 2003; Pereira, 2003, 2004c), nomeadamente no que diz respeito às dificuldades que os professores sentem na planificação e implementação de atividades de escrita, configuradas numa prática explícita, intencional e continuada. Tais dificuldades, muitas vezes justificadas pela falta de tempo, parecem ficar a dever-se muito mais a algum desconhecimento, manifestado pelos professores, relativamente às características dos géneros e dos textos. De facto, e como decorre da análise efetuada, perante uma proposta de escrita de um género que se constitui como transversal aos três ciclos do ensino básico, verifica-se que o entendimento que os diferentes professores têm sobre as suas características é distinto (em alguns casos impreciso). Tal aspeto é visível, ainda, quando se analisam as instruções dadas aos alunos para a seleção de informação. De facto, "ler com atenção e sublinhar a informação mais importante" parece ser, para os professores, a única informação de que os alunos precisam para ler e escrever para construir conhecimentos.

Ainda nesta fase, os professores foram confrontados com a análise e avaliação qualitativa das produções que os alunos realizaram. Foi-lhes pedido que, face aos critérios de avaliação que tinham definido, selecionassem e, eventualmente, acrescentassem aqueles que consideravam ser fundamentais para trabalhar com os alunos, num primeiro momento, de acordo com as dificuldades demonstradas nos textos produzidos. Relativamente às respostas dadas, todos identificaram, como aspetos fundamentais a trabalhar de forma explícita, a organização do texto (estrutura, parágrafos), a organização das ideias e a utilização de conetores. Para além disso, referiram, ainda, a necessidade de trabalhar de forma mais intencional e objetiva a leitura para seleção de informação (Pinto, 2013).

Esta observação configura um dado que importa reter. De facto, e independentemente do ano ou do ciclo, as questões da macroestrutura textual 
parecem ser a parte do "folhado textual" cujo desconhecimento por parte dos professores condiciona todo o processo de escrita e torna visíveis os problemas dos alunos, quer na seleção dos conteúdos, quer na sua distribuição e organização ao longo do texto.

Ora, uma das variáveis de que depende qualquer estratégia do escrever para aprender, para além da natureza da tarefa e do contexto de produção, diz respeito às características de quem escreve, isto é, aos conhecimentos prévios de que dispõe, não só sobre o tema, mas, também, sobre as características dos textos a produzir (Bangert-Drowns, Hurley, \& Wilkinson, 2004; Flower, 1994; Hand \& Prain, 2001; Hayes, 1996; Kieft, Rijlaarsdam, \& van den Bergh, 2008; Newell, 2006; Pereira, 2005). Se, de facto, os alunos desconhecem as propriedades que configuram os géneros e os textos estão, desde logo, impossibilitados de cumprir a tarefa que lhes foi pedida. Estamos, assim, perante um conjunto de práticas de escrita ancoradas em propostas de trabalho algo indefinidas, imprecisas, descontextualizadas e, sobretudo, que podem condicionar as aprendizagens dos alunos, aspeto sobre o qual incidiu a análise na fase 2 deste estudo.

Da análise efetuada na fase 2 poder-se-á concluir que as estratégias que os alunos utilizaram (ou a ausência destas) para selecionar a informação (o que escrever?) e o desconhecimento manifestado das características do género a produzir (como escrever?) poderão ter influenciado negativamente a escrita do texto. As produções dos alunos representaram uma conceção de texto como sinónimo de escrita de frases, algumas delas semântica e sintaticamente incorretas, sem qualquer articulação entre elas, que os alunos produziram para cumprir uma tarefa que demonstraram não saber (como) realizar.

Embora o estudo aqui apresentado não permita estabelecer uma relação entre os conhecimentos e práticas dos professores e as competências de escrita dos alunos, uma vez que não foram apresentados os dispositivos didáticos e analisados os seus efeitos na qualidade dos textos que os alunos produzem, é nossa convicção que uma prática intencional, explicitada e fundamentada nos princípios que caracterizam os diferentes géneros textuais pode, de facto, ajudar os alunos a construir e a explicitar os conhecimentos adquiridos de acordo com as funções sociocomunicativas do género a produzir (Pinto, 2014). 


\section{Notas}

1 Texto escrito no âmbito do grupo "PROTEXTOS", Departamento de Educação, Universidade de Aveiro.

2 O Programa de 2009 (PPEB) foi revogado após a realização deste estudo. Em 2015, entra em vigor um novo programa (Buescu, Morais, Rocha, \& Magalhães, 2015), no qual não há qualquer referência explícita à importância do "escrever para aprender". Ao longo do documento surgem, no entanto, como textos que os alunos deverão ser capazes de ler e escrever, "textos de características expositivas/informativas" (até ao $3 .^{\circ}$ ano) e "textos de características expositivas" (a partir do $4 .^{\circ}$ ano).

3 Os dados apresentados neste artigo fazem parte de um estudo mais alargado realizado no âmbito de um projeto de doutoramento (Pinto, 2014).

4 Gabinete de Avaliação Educacional, Ministério da Educação. Disponível em http://www.gave.min-edu.pt/np3content/?newsld=477\&fileName=IE_PF_Port41_ 2013.pdf (acedido em 12 de maio de 2013).

5 Os textos-fonte foram selecionados pela professora da turma. A investigadora não teve qualquer influência nesta escolha, nem comentou os textos selecionados previamente. Nas fases seguintes do estudo, os textos-fonte foram analisados com os formandos e identificadas fragilidades, quer a nível sintático e de pontuação, quer de conteúdo. A seleção de textos e os critérios que devem estar na base da escolha de textos foi um dos aspetos desenvolvidos na formação.

\section{Referências}

Applebee, A. (1984). Writing and reasoning. Review of Educational Research, 54(4), 577-596.

Bangert-Drowns, R. L., Hurley, M. M., \& Wilkinson, B. (2004). The effects of schoolbased writing-to-learn interventions on academic achievement: A meta-analysis. Review of Educational Research, 74(1), 29-58.

Barré-De-Miniac, C. (2003). Ecrire pour apprendre : Des pratiques à inventer. Résonances, 8, 4-9.

Bazerman, C., Little, J., Bethel, L., Cahvkin, T., Fouquette, D., \& Garufis, J. (2005). Reference guide to writing across the curriculum. USA: Parlor Press and The WAC Clearinghouse.

Blaser, C. (2007). Fonction épistémique de l'écrit : Pratiques et conceptions d'enseignants de Sciences et d'Histoire du Secondaire (Thèse de doctorat). Faculté des Etudes Supérieures, Université Laval, Quebec.

Bosch, F., \& Piolat, A. (2004). Note taking and learning: A summary of research. WAC Journal, 16, 101-113.

Bronckart, J.-P. (1997). Atividade de linguagem, textos e discursos. São Paulo: EDUC.

Buescu, H. C., Morais, J., Rocha, M. R., \& Magalhães, V. F. (2015). Programas e metas curriculares de Português do Ensino Básico. Disponível em: 
http://www.dge.mec.pt/sites/default/files/Basico/Metas/Portugues/pmcpeb_ julho_2015.pdf

Castelló, M. (2008). Escribir para aprender: Estrategias para transformar el conocimiento. Aula, 175, 15-22.

Catel, L. (2001). Écrire pour apprendre? Ecrire pour comprendre. Aster, 33, 17-47.

Dionísio, M. L. T., Pereira, M. C. M. E., \& Viseu, F. A. V. (2011). A leitura e a escrita no currículo: A presença ausente. Atos de Pesquisa em Educação, 6(1), 94-114.

Dolz, J. (2003). Ecrire pour apprendre, une stratégie pour comprendre. Résonances, 8, 8-9.

Dolz, J., Noverraz, M., \& Schneuwly, B. (2001). S'exprimer en français : Séquences

didactiques pour l'oral et l'écrit (vol. I-III). Bruxelles: De Boeck \& Larcier.

Dolz, J., Noverraz, M., \& Schneuwly, B. (2004). Sequências didáticas para o oral e a escrita: Apresentação de um procedimento. Texto de apresentação da coleção de livros didáticos "Exprimir-se em francês: Sequências didáticas". Disponível em: https://pt.scribd.com/doc/54472148/DOLZ-NOVERRAZ-SCHNEUWLY

Emig, J. (1977). Writing as a model of learning. College Composition and Communication, 28(2), 122-128.

Flower, L. (1994). The construction of negotiated meaning. A social cognitive theory or writing. Carbondale: University of Southern Illinois Press.

Franz, C. \& Soven, M. (1996). Writing in Biology: The senior project. Journal of College Science Teaching, 26(2), 111-114.

Gallego, L. V., Alvarez, M. A., \& Eulate, C. A. (2008, junho). Aprender a escribir, escribir para aprender. Paper presented at the I International Conference "Keys to student involvement in the university", Universitá de Girona.

Hand, B., \& Prain, V. (2001). Teachers implementing writing-to-learn strategies in junior secondary science: A case study. Science Education, 86(6), 737-755.

Hayes, J. R. (1996). A new framework for understanding cognition and affect in writing. In C. M. Levy \& S. Ransdell (Eds.), The science of writing theories, methods, individual differences, and applications (pp. 1-27). Mahwah (NJ): Lawrence Erlbaum Associates.

Kieft, M., Rijlaarsdam, G., \& van den Bergh, H. (2008). An aptitude-treatment interaction approach to writing-to-learn. Learning and Instruction, 18(4), 379-390.

Knight, L. J., \& McKelvie, S. J. (1986). Effects of attendance, note-taking, and review on memory for a lecture: Encoding vs. external storage functions of notes. Canadian Journal of Behavioral Science, 18, 52-61.

Marcuschi, L. A. (2005). Gêneros textuais: Definição e funcionalidade. In A. P. Dionísio, A. R. Machado, \& M. A. Bezerra (Eds.), Gêneros textuais e ensino (pp. 18-36). Rio de Janeiro: Lucerna.

Newell, G. E. (2006). Writing to learn: How alternative theories of school writing account for student performance. In C. A. MacArthur, S. Graham, \& J. Fitzgerald (Eds.), Handbook of writing research. New York: Guilford Press.

Pereira, L. A. (2003). Para uma didáctica da escrita no Ensino Básico: Teses, pressupostos e condições de possibilidade. In A. Neto, J. Nico, J. C. Chouriço, 
P. Costa, \& P. Mendes (Eds.), Didácticas e metodologias da educação Percursos e desafios (pp. 109-116). Évora: Universidade de Évora.

Pereira, L. A. (2004a). A língua escrita no(s) $1^{\circ}$ (s) ciclo(s) do Ensino Básico. Para uma definição de esquemas didácticos em ensino da produção de escritos e leitura. Intercompreensão, 11, 49-59.

Pereira, L. A. (2004b). Des discours sur les pratiques aux pratiques d'enseignement. In C. Barré-De Miniac, C. Brissaud, \& M. Rispail (Eds.), La littéracie : Conceptions théoriques et pratiques d'enseignement de la lecture-écriture (pp. 319-333). Paris: L'Harmattan.

Pereira, L. A. (2004c). Imagem da escrita de docentes do Ensino Básico. Para uma (re)definição do papel do professor que ensina a escrever. In P. Cantero, F. Liñares, \& E. Carollo (Orgs.), Actas del VIII Congreso Sociedad Española de Didáctica de la Lengua y la Literatura (pp. 133-145). Barcelona: SEDLL.

Pereira, L. A. (2005). O ensino da escrita na escola: Um objecto plural. In J. A. Carvalho, L. Barbeiro, A. Silva, \& J. Pimenta (Eds.), A escrita na escola, hoje: Problemas e desafios. Actas do II Encontro de Reflexão sobre o Ensino da Escrita (pp. 5567). Braga: Instituto de Educação e Psicologia, Universidade do Minho.

Pereira, L. A. (2008). Escrever com as crianças. Como fazer bons leitores e escritores. Para crianças dos 0 aos 12 anos. Porto: Porto Editora.

Pereira, L. A., \& Cardoso, I. (2013). A sequência de ensino como dispositivo didático para a aprendizagem da escrita num contexto de formação de professores. In L. A. Pereira \& I. Cardoso (Eds.), Reflexão sobre a escrita. O ensino de diferentes géneros de textos (pp. 33-56). Aveiro: Universidade de Aveiro.

Pietro, J.-F. D., Erard, S., \& Kaneman-Pougatch, M. (1996). Un modèle didatique du débat : De l'objet social à la pratique scolaire. Enjeux, 39, 100-129.

Pietro, J.-F. D., \& Schneuwly, B. (2003). Le modèle didactique du genre : Un concept de l'ingénierie didactique. Les Cahiers Théodile, 3, 27-52.

Pinto, M. O. (2013, julho). Escrever para aprender a expor - Práticas de escrita no Ensino Básico. Comunicação apresentada no V Encontro Internacional de Reflexão sobre a Escrita, Universidade de Aveiro.

Pinto, M. O. (2014). Escrever para aprender: Estratégias, textos e práticas (Tese de doutoramento). Universidade de Aveiro, Aveiro.

Pinto, M. O., \& Pereira, L. A. (2006, dezembro). Escrever para aprender: Experiências didácticas. Comunicação apresentada no III Encontro de Reflexão sobre o Ensino da Escrita, ESE de Leiria, 7 de dezembro.

Piolat, A., \& Boch, F. (2004). Apprendre en notant et apprendre à noter. Cognitive Psychology and Education, 16, 133-152.

Reis, C. C., Dias, A. P., Cabral, A. T. C., Silva, E., Viegas, F., Bastos, G., ...Pinto, M. O. (2009). Programas de Português do Ensino Básico. Lisboa: Ministério da Educação, DGIDC.

Rice, R. (1998). Scientific writing. A course to improve the writing of science students. Journal of College Science Teaching, 27(4), 267-272.

Schneuwly, B., \& Dolz, J. (Eds.). (2004). Gêneros orais e escritos na escola. Campinas: Editora Mercado de Letras. 
Stahl, N. A., King, J. R., \& Henk, W. A. (1991). Enhancing students' note-taking through training and evaluation. Journal of Reading, 34(8), 614-622.

Tynjälä, P., Mason, L., \& Lonka, K. (2001). Writing as a learning tool - An introduction. In P. Tynjälä, L. Mason, \& K. Lonka (Eds.), Writing as a learning tool - Integrating theory and practice (pp. 7-22). Netherlands: Kluwer Academic Publishers. 


\title{
WRITING TO LEARN IN COMPULSORY EDUCATION: FROM TEACHERS' CONCEPTIONS... TO STUDENTS' PRACTICES
}

\begin{abstract}
This article focuses on the issue of writing as a knowledge construction object and highlights the importance of teacher mediation on the learning of this type of writing. The goal of this text is to present some results from a study that initially analysed the conceptions and practices of teachers from each of the three cycles of Portuguese compulsory education (K-1 to K-9), and, afterwards, the activities of information selection and of writing an expository text by students from a fourth grade class $(\mathrm{K}-4)$. Results show a lack of specific criteria in evaluating writing and the use of writing instructions that are insufficient in guiding the students to write a specific text (genre). On the students' part, they revealed difficulties in both information selection and in the production of the requested genre, since their final text presents a collage of texts, without the textual configuration required by the genre.
\end{abstract}

Keywords

Write to learn; Written exposition; Compulsory education; Text genres

\section{ESCRIBIR PARA APRENDER EN LA EDUCACIÓN BÁSICA: DESDE LAS CONCEPCIONES DE LOS PROFESORES... HASTA LAS PRÁCTICAS DE LOS ALUMNOS}

\section{Resumen}

Este artículo se basa en el asunto de la escritura como instrumento en la construcción del conocimiento y resalta la importancia de los profesores en su papel de mediadores del aprendizaje. El propósito de este trabajo es presentar algunos resultados de un estudio en el cuál se analiza, en un primer momento, las concepciones y prácticas de los profesores de los tres ciclos de la educación básica y, posteriormente, las actividades de selección de la 
información y de escritura de una exposición por parte de alumnos de una clase de cuarto grado. Los resultados muestran una ausencia de criterios específicos de evaluación y el uso de algunas instrucciones escritas poco claras que guíen a los alumnos en la producción de un determinado (género de) texto. Estos, a su vez, mostraron dificultades tanto en la selección de la información, como en la producción del tipo de texto pedido, una vez que el texto final presenta partes de textos copiados de textos leídos sin ninguna configuración textual requerida por el género.

Palabras-clave

Escribir para aprender; Exposición escrita; Educación básica; Géneros textuales

Recebido em janeiro/2016

Aceite para publicação em junho/2016

i Escola Superior de Educação, Instituto Politécnico de Lisboa, Portugal.

ii Departamento de Educação, Universidade de Aveiro, Portugal.

Toda a correspondência relativa a este artigo deve ser enviada para: Mariana Oliveira Pinto, Escola Superior de Educação de Lisboa, Departamento de Educação em Línguas, Comunicação e Artes, Campus de Benfica do IPL, 1549-003 Lisboa. Email: mariana.opinto@gmail.com 


\section{Anexo}

\section{Texto fonte 1: http://ap12aanimais.forumeiros.com/t46-enguia (adaptado).}

\section{Enguia}

\section{Introdução}

A enguia é um peixe. Existem várias espécies de enguias mas todas pertencem ao género Anguilla. Este animal nasce no oceano Atlântico onde ainda é uma espécie de larva, é arrastada pelas correntes maritimas, passado alguns anos vão para ribeiros e rios onde se irão reproduzir e morrer.

Este peixe tem um ciclo de vida no mar e na água doce, onde se reproduz e morre. .

\section{Características}

O seu corpo é longo e cilindrico que possui barbatana dorsal que se une à cauda, escamas ovais, o seu focinho cónico e tem 2 narinas e no seu maxilar existem dentes pequenos mas aguçados e fortes. É mais ativa durante a noite. Esta também tem a capacidade de poder sair da água e movimentar-se nas margens mais húmidas, para se poder introduzir num outro meio aquático mais próximo.

\section{Habitat/Distribuição}

A enguia vive maioritariamente no fundo dos rios e barragens, esta prefere rios com águas correntes, oxigenadas, pouco frias e leitos com areia ou lodo ou com vegetação densa. Este animal existe em abundância, no nosso país, devịdo à proximidade que a foz está do rio e também porque chove muito anualmente. Os machos normalmente encontram-se nos estuários e as fêmeas na parte superior dos cursos de água. Podem-se encontrar enguias nos estuários dos rios que desaguam no oceano Atlântico, mar do Norte, no Báltico e no Mediterrâneo e podem também aparecer no mar Negro.

\section{Alimentação}

A enguia alimenta-se de vários tipos de alimento, logo é omnivora. O seu alimento pode ser matéria mineral, material vegetal (como algas mais pequenas), detritos, macro-invertebrados aquáticos e alguns peixes. Em alguns estuários elas alimentam-se de caranguejos e bivalves. Mas em água doce ela pode ingerir larvas aquáticas.

\section{Reprodução}

Após uns longos 5 ou 12 anos estas criaturas no inicio do outono regressam ao mar dos Sargaços, onde se vão reproduzir. Esta actividade é feita nas profundezas, por volta dos 300 aos 700 metros, onde a temperatura é de $16^{\circ} \mathrm{C}$ ou $17^{\circ} \mathrm{C}$. Cada fêmea pode produzir 1 milhão de ovos 
Texto fonte 2: http://www.pescalazer.com/peixes/enguia.html (adaptado).

$$
\text { - Enguia }
$$

7 Esta espécie foi ao longo dos séculos penetrando em quase todos os estuários da major parte dos paises europeus incluindo Portugal. No nosso pais a enguia pode ser encontrada em praticamente todos os cursos de água doce. Só em meados do século $X X$ se reconheceu cientificamente o verdadeiro ciclo biológico desta espécie. Nascendo no Oceano Atlântico, no Mar dos Sargaços, entre as Bahamas e Bermudas, como larvas são arrastadas ao longo de um periodo de 2 a 3 anos pelas correntes oceânicas até às costas europeias onde inicia uma outra etapa da sua metamorfose, já como pequenas enguias ou enguias de vidro (transparentes) vão subindo ao longo dos rios e ribeiras onde adquirem o estado adulto para mais tarde regressarem de novo à origem onde se reproduzirão e morrerão.

É uma espécie marinha com uma história migratória e com um ciclo de vida em água doce e outro no mar. Possui um corpo muito alongado e cilindrico, com aparência serpentiforme, de dorso esverdeado e ventre claro, com escamas minúsculas e ovais e uma barbatana dorsal que se une à caudal e anal e com as peitorais curtas. Apresenta um focinho pequeno e cónico com 2 pares de narinas e de boca larga onde a maxila inferior ultrapassa a superior, ambas com pequenos dentes muito fortes e aguçados.

Tem uma enorme versatilidade quer de se deslocar em qualquer curso de água quer de viver em águas bem ou mal oxigenadas, procurando sempre os obstáculos para se proteger ou camuflar, desenvolvendo grande parte da sua actividade à noite. Possui ainda a capacidade de poder sair da água e movimentar-se nas margens mais húmidas, chegando mesmo a utilizar esta particularidade para se introduzir num outro meio aquático mais próximo.

A fêmea é maior que o macho, atingindo normalmente medidas que vão dos dos $30 \mathrm{~cm}$. a $1 \mathrm{~m}$., excepcionalmente pocerão chegar a $1,5 \mathrm{~m}$. com pesos que atingem os 3 ou $4 \mathrm{~kg}$., no entanto já existem registos de mais de $5 \mathrm{~kg}$.

Caicula-se que a Enguia tem um limite de idade superior a 20 anos, smbora em média a fêmea possa viver até aos 18 anos e o macho até aos 14/15.

A Enguia é um peixe omnivoro, e sobretudo carnivoro, muito voraz. Após entrar no ciclo de água doce alimenta-se de pequenos peixes, crustáceos, anfibios, grandes larvas, tudo que seja animal vivo ou

Após um longo ciclo de vida em água continentais, entre 5 e 12 anos, no início do Outono a Enguia empreende o regresso ao Mar dos Sargaços, onde tem lugar a reprodução, sendo a postura feita a profundidades que vão dos 300 aos 600700 metros, quando a temperatura estabiliza nos $16^{\circ} \mathrm{C}$ ou $17^{\circ} \mathrm{C}$. Cada fêmea pode reproduzir até 1 milhão de ovos. A incubação dura mais ou menos 30 dias a após a eclosão das larvas estas ficam dissimuladas em pequenas algas em deriva e logo arrastadas pela chamada corrente do Golfo que cruza o oceano. 